\title{
Unearthing Conceptions about Types of Chemical Bonding Through the Use of Tiered Worksheets - A Case Study
}

\author{
Ruby Hanson \\ Faculty of Science Education \\ University of Education, Winneba, Ghana
}

\begin{abstract}
The use of tiered worksheets and interpretive procedures to find out teacher trainees' conceptions about basic types of chemical bonds are presented in this paper. The research was carried out with 71 first year Chemistry education teacher trainees purposely sampled from two teaching universities. Their answers were analysed in order to understand their knowledge structures about chemical bonding. Results from the activity indicated that more than $88 \%$ of the chemistry education teacher trainees had some misconceptions about chemical bonding, which stemmed from their idiosyncratic interpretations about the nature of matter. The requirement for justification of answers which was embedded in the second tier unearthed these misconceptions. Some suggestions were made for other effective teaching approaches to enhance the trainees' conceptual understanding of chemical bonds.
\end{abstract}

\section{Introduction}

The study of chemistry is a challenge for students who fail to master authentic basic concepts about the nature of matter in their early interactions with formal science and their environment. Matter is said to be neither created nor destroyed in the course of a chemical reaction, but changes from one form to another - the law of conservation of matter. This implies that matter retains its elemental components even as it results in different combinations, forms and outcomes, during interactions with each other. Whatever it is that upholds these new outcomes (of particulate interactions) rests upon the nature of the combining (reacting) elemental species or reactants and the kinds of bonds (energies) that hold them together chemically, so that new 'permanent' species (products) result. The concept of chemical reactions and their resulting chemical compounds have been difficult for students to comprehend, partly because of its inherent abstract nature and students' own faulty beginnings- either from their improper interpretations of nature before formal introduction of science, inappropriate textbooks, teachers' inadequate content knowledge, or poor pedagogical skills. Chemical reactions are said to be abstract because what happens at the particulate level is not easily perceived for the creation of mental images. Their definitions of chemical phenomena arebased on changes at the macro level where they make observations such as colour change, the formation or dissolution of a solid, evolution of a gas, and the evolution or absorption of heat. Hardly can they imagine how ions, molecules and atoms look like or interact at the particulate level during compound formation.

Knowing about students' conceptions prior to lesson preparation can be very useful for teachers, as it enables them to prepare adequately to tackle conceptual challenges in their classrooms. If teachers' or students' knowledge bases are faulty or have gaps, they could result in further faulty reasoning and deepened conceptual misunderstanding. Chemical bonding is one such topic for which students' own ideas are often faulty and so must first be sought and used as a starting point for teaching $[1,2]$. Without doubt, chemical bonding is an essential, yet difficult concept for chemists. Multiple studies have described numerous misconceptions that students have about the concept of bonding [3]. Many of these misconceptions are robust and remain even after instruction. According to Hanson et al. [4], students' understanding of most basic chemistry concepts are based on their ability to scientifically express themselves on issues of chemical bonding and compound formation.

The interest that several researchers have shown in students' understanding of chemical bonding in particular is because it is a pre-requisite to understanding the behaviour of atoms and compounds. Such understanding is fundamental to subsequent learning of various other conceptual frameworks in chemistry, including chemical equilibrium, thermodynamics, molecular structure, and chemical reactions. In science education literature, students' understanding and misconceptions about metallic, ionic, and covalent bonding have revealed prevalent and consistent misconceptions across a range of ages and cultural settings. Hanson [1] reported in a study that teacher trainees (herein referred to as trainees) were 
confused about the concepts of covalent and ionic bonds. Some of them conceptualised the sodium and chlorine atoms as being held together by covalent bonds. They intimated that sodium chloride existed as molecules which were held together in a solid form by covalent bonds. Others thought that the atoms were rather bonded covalently as individual discrete molecules but joined as a crystal lattice by ionic bonds. Coll and Taylor [2] found from their studies that students have misconceptions and learning difficulties concerning atomic structure, chemical bonding and matter. Griffiths and Preston [5]found that students regard matter as continuous while Harrison and Treagust [6] found in their study that students prefer models of atoms and molecules that depict entities as discrete, concrete structures. How students perceive matter affects their mental models of bonds in compounds.

In a similar study, Peterson, Treagust and Garnett [7] investigated Grade-11 and Grade-12 students' misconceptions of covalent bonding and structure and found that they did not acquire a satisfactory understanding of covalent bonding and held misconceptions regarding the unequal sharing and position of an electron pair in a covalent bond. They related electron sharing to covalent bonding, yet did not consider the effect of electronegativity and the resultant unequal electron sharing. They had fuzzy ideas about polar covalent bonding and covalent bonding as the role of electronegativity in polar covalent bonding was disregarded. Taber [8] investigated students' misconceptions dealing with ionic bonding and found that students had difficulty in understanding ionic bonding. He stated that many chemistry students overemphasise the process of electron transfer and used the notion of ion-pairs as molecules. Their ideas were constrained by inappropriate understanding of valency combinations. According to his findings, some students believed that a chemical bond was a physical entity. Some imagined that ionic compounds existed as discrete molecules. Undergraduate chemistry students have also been known to hold misconceptions related to electronegativity, bonding, geometry, and microscopic representations [9]. Taskin and Bernholt [10] also found out that misinterpretation of chemical reactions and their meanings persist even among academically elect and premier university students.

In an Australian study, students were presented with samples of metallic, ionic, and covalent substances, and asked to describe the bonding in them. Their responses revealed that they used simple, realistic mental models for chemical bonding. In contrast, other studies revealed that learners' mental models of bonding were sophisticated, yet they struggled to explain the physical properties of covalently bonded substances [11]. This was a clear case of rote learning of theories without indepthunderstanding of the nature of matter, and inability to apply them in real life situations. These assertions clearly showed the diverse dimensions in which matter is conjectured because of their inabilities to perceive the real bonding structures within species.

Teachers often try to use models and analogies to enable students' to form mental models of abstract concepts without success. These situations arise when students are fixed in their own ideas such that their permanencies do not allow the acceptance of a new but plausible idea. One problem that students have with the concept of bonding is how to visualise bonds as existing between central species and bonding atoms but not that which exists between particles of the central species [9]. The idea that species should attain 'full electron shells' and that a bond should exist between two atoms only, is yet another limiting factor to their understanding of chemical bonding. The concept of full outer shell heuristic is of little help in discussing phenomena like bond polarity, hydrogen bonding, van der Waals' forces and a few other bonding concepts as it has limitations, such that overdependence on it could form the basis for alternative conceptions. More challenging is how to mentally perceive and understand the different types of chemical bonds that exist among different compounds, some of which could be formed from the same atoms through different combinations as a result of different chemical bonds.

Some researchers have argued that the topic of polar covalent bonding is often presented in a problematic way in text books, such that, students are left to interpret chemical bonding concepts in a multitude of ways [12]. Despite the widely understood notion that covalent bonding, polar covalent bonding, and ionic bonding are a continuum, chemistry educators and textbooks [12] still present this information as three distinct types of bonding. Therefore, students' poor conceptions about chemical bonding have to be sought through diagnostic processes as a basis for further effectual work. Methods such as paper and pencil test, thinkaloud interviews, concept mapping, concept text, concept cartoons and two-tiered tests have all been used in earlier researches as a way of identifying misconceptions in chemistry, chemical bonds inclusive [4]. Using diagnostic diagrammatic probes could have the potential to unearth students' mental models about concepts and enable them to acquire skills to build scientific models. Since the main goal of chemistry is to guide students to build vivid authentic mental models of chemical phenomena, then using diagrams could be one such way as it has the capacity to facilitate and challenge students' higher order thinking skills. It could also enable them to build their imaginative powers as no contextual change text would.

Diagrammatic worksheets have been found to be simple and yet effective resources that embed the 
constructivist principle to enable students to construct concepts with ease. They are structured to encourage them to build knowledge and allow for full participation in class, even as they take responsibility for their actions. They inadvertently encourage free expression of thoughts. They are particularly useful when other standard and technological resources are not available for use to build mental models. Worksheets help learners to gain scientific concept and process skills as users are often required to observe, analyse, interpret, record and synthesise, in order to form mental images and conceptualise ideas. This study therefore set out to find out if Ghanaian teacher trainees also have conceptual problems with chemical bonding as revealed in studies across the world, using a simple diagnostic worksheet, in this case.

\section{Purpose of the Study}

While research studies on chemical bonding have focused on identification of alternative conceptions in some parts of the world, none of such has been done in Ghana. Neither were strategies for identification and remediation of alternative conceptions on chemical bonding among teacher trainees in particular in Ghana found. Chemical bonding is part of first year undergraduate chemistry course as it is a pre-requisite to understand other chemical phenomena. Thus, it is important to assess trainees' levels of understanding in order to use their prior knowledge as a basis for teaching and remediation before they build up other higher concepts on faulty bases. In this study the interest is on whether diagnostic diagrams, presented as worksheet activities, could be used as an effective tool to unearth trainees' innate knowledge structures about chemical bonds. The study used an easily accessible and assessable diagnostic probe.

The study was guided by three research questions.

1. What are some common teacher trainees' reasoning patterns about chemical bonds?

2. What is the possibility of using a diagnostic diagrammatic probe in unearthing teacher trainees' conceptions about chemical bonding?

3. What aspects of the worksheet were suitable for unearthing, deconstructing and building concepts about chemical bonding?

\section{Method and data analysis}

In this study, an interpretive qualitative investigation into trainees' own ideas was adopted, with quantitative underpinnings. The interpretive paradigm allowed for rich contextual information and provided insights into individual behaviours and assumptions in order to uncover emic views [13]. It also limited any ambiguities that could arise. The quantitative analysis gave an overview of trainees' performance. The sample comprised of a cosmopolitan group of 71first year chemistry education teacher trainees from two teacher education universities with comparable admission criteria from all over Ghana. The research focused on teacher trainees (herein referred to as trainees) because teacher education programmes are a reasonable place to start introducing nouvelle ways of diagnosing conceptual understanding and remediation. University A had 32 trainees while B had 39 trainees in their first year chemistry class. These trainees participated in the study because the topic of chemical bonding was taught at their level. They were expected to have learned about chemical bonding in disciplines such as physical, inorganic and organic chemistry in their respective pre-tertiary institutions. A diagnostic diagrammatic probe adapted from the Royal Society of Chemistry (RSC) resource book [14], with a reliability index of 0.83 , was used to collect data about the trainees' understanding of chemical bonding. The diagnostic diagram sheet containing 18 models of elements and compounds was administered to the two groups, scored, and analysed statistically (quantitative) and interpretively (qualitative) to ascertain their prior naive constructions, deconstructions, and reconstructions, as they ascribed reasons for first tier choices of types of chemical bonds. A selected sample of models from the diagnostic sheet is shown as Figure 1.

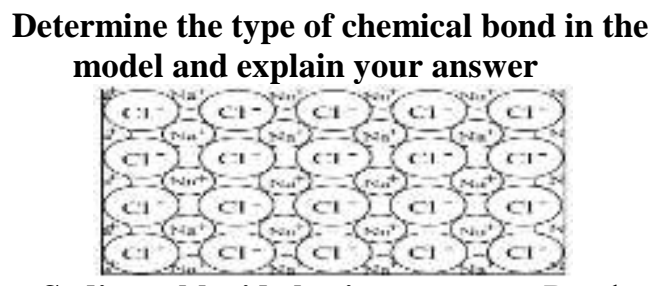

Sodium chloride lattice: ............Bond

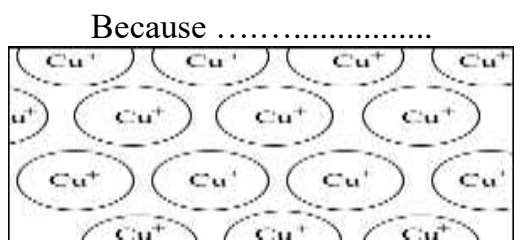

Copper metal lattice: ...........Bond

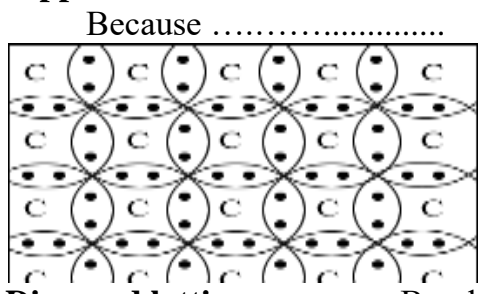

Diamond lattice: ...........Bond

Because 


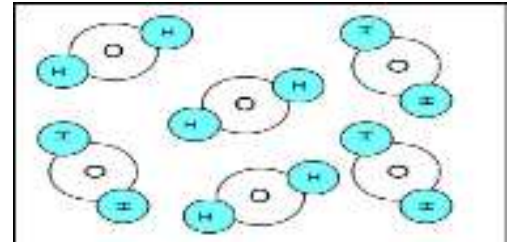

Liquid water: Bond

Because .....................

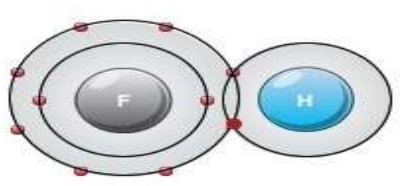

Hydrogen fluoride molecule: Bond

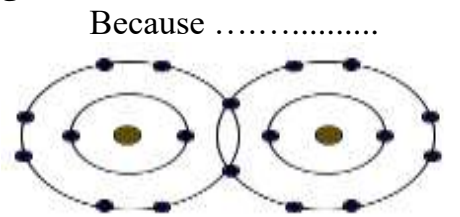

Fluorine molecule: Bond

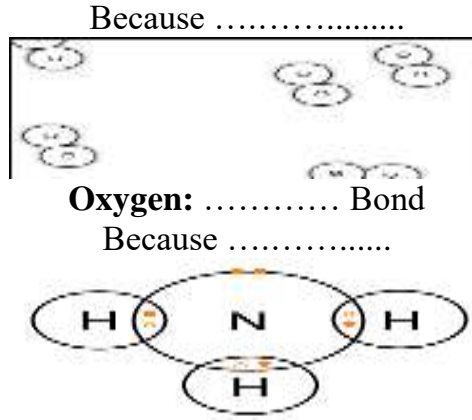

Ammonia molecule: Bond

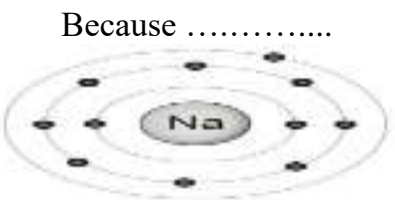

Sodium atom: Bond

Because

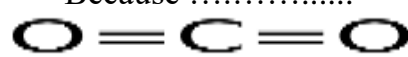

Carbon dioxide molecule:

Because

Figure 1. Selected models from the diagnostic Activity Sheet

This was followed by a focus group discussion (Appendix A).

The analysis was integrative as it was one from an interactive process and its temporal structural context. Discourses were extracted from trainees' language. Narratives were composed from the interviews so as to obtain an in-depth view about the context. According to Roth and Hsu [15], the prevailing ideas of a community could always be unearthed through extracting their views from interviews or other verbal expressions.

\subsection{Scoring}

The entire exercise was marked over a total of 36 marks as each correct (two-tiered or paired) item attracted two full marks. However, each individual tier was assigned one mark for a correct score for ease of comparison of changes in the tiers. Reasons for choices were analysed and interpreted by the researcher in order to understand participants' naive conceptual frameworks for further research studies. Some of the chemical bonds expected to be identified from the diagnostic model representations (see Figure 1) were ionic, covalent, metallic, delocalised, hydrogen, and van der Waals forces (dipole-dipole, induced dipole). Total scores below 12 marks were classified as a demonstration of poor conception about chemical bonds. Total scores between 13 and 24 (inclusive) were judged as exhibition of partial conception. Scores between 25 and 36 (all values inclusive) were deemed as sound conception. Answers to items were classified as misconceptions about a particular chemical bond when about 10 per cent of the sample got their answers wrong and partial conception when five (5) percent made wrong choices. According to Hanson and Oppong [16], if at least $10 \%$ of a given sample has difficulty understanding scientific concepts then they have alternative conceptions. They added that any percentage lower than 10 must not be overlooked otherwise most wrong concepts would escape remediation, if partial conception was accepted as authentic responses. However, this study pegged the threshold level for misconceptions at a minimum level of $10 \%$ failure.

The sample in this study is representative of students taught with a curriculum in which bonding concepts were presented as separate entities [8]. Thus, analysis of data was done from this perspective as trainees' understanding was interpreted.

\section{Results and Analysis}

The trainees' responses were analysed both qualitatively and quantitatively by separating them into different levels of understanding from which frequencies were worked out for comparison. Their reasons or second tier responses were also analysed for their reasoning patterns. It must be noted that where a bond had significant polarity its description as polar, rather than covalent were also accepted as correct. Thus, polar covalent bond was accepted for some apparent covalent species. The term van der Waal forces was assumed as interchangeable with induced dipole-dipole forces.

The general performances of both universities in the first (choice) tier only are presented as Table 1 . 
Table 1. General performance (in \%) of trainees in Univ A \& B for Tier 1

\begin{tabular}{|l|c|l|c|l|}
\hline Score & F(Univ A) & $\mathbf{\%}$ & F(Univ B) & \% \\
\hline $0-8$ & 10 & 31 & 10 & 26 \\
\hline $9-13$ & 12 & 38 & 18 & 46 \\
\hline $14-18$ & 10 & 31 & 11 & 28 \\
\hline Total & 32 & 100 & 39 & 100 \\
\hline
\end{tabular}

$\mathrm{F}=$ Frequency; $\%$ = Percentage; Univ = University

Quantitative analysis of data from Table 1 shows that majority of students, $69 \%$ (22 out of 32 ) trainees and $72 \%$ of 39 trainees had poor and partial understanding of chemical bonding in the diagnostic diagrammatic probe exercise.Their performance in the 2-tiered section where reasons were assigned was also assessed. If a reason was correct, in accordance with the expected answer, it was marked correct. This is presented as Table 2 .

Table 2. General performance (in \%) of trainees in Univ A \& B for Tier 2

\begin{tabular}{|l|c|l|c|l|}
\hline Score & F(Univ A) & \% & F(Univ B $)$ & \% \\
\hline $0-8$ & 16 & 50 & 19 & 49 \\
\hline $9-13$ & 10 & 31 & 13 & 33 \\
\hline $14-18$ & 6 & 19 & 7 & 18 \\
\hline Total & 32 & 100 & 39 & 100 \\
\hline
\end{tabular}

$\mathrm{F}=$ Frequency $\%$ = Percentage; Univ = University

From Table 2, it was observed that majority of the trainees performed poorly in the reasoning section as most of the answers they gave for making their choices were wrong. About $81 \%$ (26 trainees) and $82 \%$ (36) of the trainees in A and B respectively, possessed poor and partial misconceptions about chemical bonds. It was observed that some trainees identified the bond types correctly but gave wrong reasons for their choices. Incidentally some chose some wrong bond types but had the expected reason for a wrong chemical bond type.

Table 3. Performance of trainees (in \%) for combined Tiers $1 \& 2$

\begin{tabular}{|l|c|l|l|l|}
\hline Score & F(Univ A) & \% & F(Univ B) & \% \\
\hline $0-10$ & 19 & 59 & 22 & 56 \\
\hline $11-25$ & 10 & 31 & 12 & 31 \\
\hline $26-36$ & 3 & 9 & 5 & 13 \\
\hline Total & 32 & 100 & 39 & 100 \\
\hline
\end{tabular}

These lapses reduced the percentages of those who showed apparent correct conceptions in Table 1 to 9\% and 13\% for Universities A and B respectively. In a further analysis, the type of chemical bond and the reason for that identification were tied and marked so that a wrong reason for a correct bond type or vice versa was scored as wrong and demonstrated misconception. The outcome is presented as Table 3 .

From Table 3, when the answers were tied so that a correct bond type could only be correct if the reason behind it was correct, the trainees performed even less credibly. About 90\% (29 out of 32) and $87 \%$ (34 out of 39) poor and partial misconceptions were identified for trainees in Universities A and B, respectively. That comes to an average of $88.5 \%$ total alternative conceptions among the trainees. With a more rigorous assessment of answers, the trainees' weaknesses became more apparent. Interpretive analysis of items revealed that trainees in University B performed slightly better on the diagnostic assessment than trainees in University A. Ionic bonding models were the ones most easily identified by all the trainees, while models on covalency which also depicted some polarity, dipoledipole, double or other van der Waals' forces were the least identified. Remediation would be required for trainees in both universities as more than $10 \%$ of each sample scored less than half the total mark required in the diagnostic probe.

The analyses of items with the expected and wrong answers are shown for both universities. The analysis for University A is presented as Table 4.

Table 4. Analysis of items for University A $(\mathrm{N}=32)$

\begin{tabular}{|c|c|c|c|c|}
\hline Item & $\mathbf{C}$ & $\begin{array}{l}\text { Correct } \\
\text { answers }\end{array}$ & $\mathbf{W}$ & Wrong answers \\
\hline $\begin{array}{l}1 . \mathrm{NaCl} \\
\text { lattice }\end{array}$ & 20 & Ionic & 2 & $\begin{array}{l}\text { Covalent; } \\
\text { metallic }\end{array}$ \\
\hline $\begin{array}{l}\text { 2.Diamo } \\
\text { nd lattice }\end{array}$ & 1 & Covalent & 21 & $\begin{array}{l}\text { Crystal; dative; } \\
\text { metallic }\end{array}$ \\
\hline $\begin{array}{l}3 . \mathrm{C}_{6} \mathrm{H}_{6} \\
\text { molecule }\end{array}$ & 3 & Covalent & 9 & $\begin{array}{l}\text { Triple bond; H- } \\
\text { bonding; carbon } \\
\text { bonding; } \\
\text { covalent; polar } \\
\text { covalent; ionic; } \\
\text { no idea }\end{array}$ \\
\hline $\begin{array}{l}\text { 4. } \mathrm{Cu}(\mathrm{s}) \\
\text { lattice }\end{array}$ & 5 & Metallic & 27 & $\begin{array}{l}\text { None; } \\
\text { covalent; copper } \\
\text { II; dative covant }\end{array}$ \\
\hline $\begin{array}{l}5 . \mathrm{HF} \\
\text { molecule }\end{array}$ & 17 & $\begin{array}{l}\text { Covalent; } \\
\text { polar }\end{array}$ & 5 & $\begin{array}{l}\text { Ionic bond; H- } \\
\text { bonding none }\end{array}$ \\
\hline $6 . \mathrm{H}_{2} \mathrm{O}(\mathrm{l})$ & 18 & $\begin{array}{l}\text { Covalent; } \\
\text { VDF; polar; } \\
\text { H-bonding; } \\
\text { dipole- } \\
\text { dipole }\end{array}$ & 14 & $\begin{array}{l}\text { Chemical; ionic; } \\
\text { covant }\end{array}$ \\
\hline $\begin{array}{l}\text { 7. } \mathrm{F}_{2} \text { mole } \\
\text { cule }\end{array}$ & 9 & Covalent & 3 & $\begin{array}{l}\text { None; covant; } \\
\text { not sure; dative; } \\
\text { polar covalent; } \\
\text { ionic }\end{array}$ \\
\hline $\begin{array}{l}8 . \\
\mathrm{NaNO}_{3}(\mathrm{a} \\
\text { q) }\end{array}$ & 3 & $\begin{array}{l}\text { Covalent; } \\
\text { induced } \\
\text { dipole }\end{array}$ & 29 & Ionic; none \\
\hline 9. $\mathrm{O}_{2}(\mathrm{~g})$ & 27 & $\begin{array}{l}\text { Covalent; } \\
\text { double } \\
\text { bond; VDF }\end{array}$ & 5 & $\begin{array}{l}\text { Intermolecular; } \\
\text { hydrogen; } \\
\text { molecular; } \\
\text { interatomic; }\end{array}$ \\
\hline
\end{tabular}




\begin{tabular}{|c|c|c|c|c|}
\hline & & & & none \\
\hline $10 . S_{8}$ & 23 & Covalent & 9 & $\begin{array}{l}\text { Ionic; Lewis; } \\
\text { dipole; crystal }\end{array}$ \\
\hline $\begin{array}{l}11 . \mathrm{Na} \\
\text { atom }\end{array}$ & 2 & $\begin{array}{l}\text { Intra-atomic } \\
\text { forces of } \\
\text { similar } \\
\text { nature or no } \\
\text { bonding }\end{array}$ & 30 & $\begin{array}{lr}\text { Ionic; } & \text { none; } \\
\text { atomic } & \text { bond; } \\
\text { metallic; } & \text { sodium } \\
\text { atom } & \end{array}$ \\
\hline $\begin{array}{l}\text { 12. } \mathrm{AlCl}_{3} \\
\text { dimer }\end{array}$ & 5 & $\begin{array}{l}\text { Polar; dative } \\
\text { covalent }\end{array}$ & 27 & $\begin{array}{l}\text { Metallic; ionic; } \\
\text { single bond; not } \\
\text { a bond }\end{array}$ \\
\hline $\begin{array}{l}13 . \mathrm{CO}_{2} \\
\text { molecule }\end{array}$ & 26 & $\begin{array}{l}\text { Covalent; } \\
\text { polar; } \\
\text { double(sigm } \\
\mathrm{a}+\text { pi) }\end{array}$ & 6 & $\begin{array}{l}\text { Not a bond; } \\
\text { carbon bond; H- } \\
\text { bond; ionic }\end{array}$ \\
\hline $\begin{array}{l}14 . \mathrm{CH}_{3} \mathrm{C} \\
\mathrm{OOH} \\
\text { dimer }\end{array}$ & 8 & $\begin{array}{l}\text { Covalent; } \\
\text { polar; H- } \\
\text { bonding }\end{array}$ & 24 & $\begin{array}{l}\text { Dative covalent; } \\
\text { covalent; }\end{array}$ \\
\hline $\begin{array}{l}15 . \mathrm{I}_{2} \\
\text { Lattice }\end{array}$ & 10 & $\begin{array}{l}\text { Covalent; } \\
\text { VDF }\end{array}$ & 22 & $\begin{array}{l}\text { Ionic; metallic; } \\
\text { none; double; } \\
\text { Fe; crystal }\end{array}$ \\
\hline $\begin{array}{l}16 . \mathrm{NH}_{3} \\
\text { molecule }\end{array}$ & 26 & $\begin{array}{l}\text { Covalent; } \\
\text { polar }\end{array}$ & 6 & $\mathrm{NH}_{3}$; ionic; triple \\
\hline $\begin{array}{l}17 \mathrm{MgO} \\
\text { lattice }\end{array}$ & 11 & Ionic & 21 & $\begin{array}{l}\text { MgO; polar } \\
\text { covalent; } \\
\text { metallic }\end{array}$ \\
\hline $\begin{array}{ll}18 . & \mathrm{HCl} \\
\text { (1) } & \end{array}$ & 9 & $\begin{array}{l}\text { Covalent; } \\
\text { polar; VDF }\end{array}$ & 23 & $\begin{array}{l}\text { Hydrogen; ionic; } \\
\text { dative; }\end{array}$ \\
\hline
\end{tabular}

$\mathrm{VDF}=$ van der Waal's forces; $\mathrm{C}=$ Trainees' correct answers; $\mathrm{W}=$ Trainees' wrong answers

Table 4 shows the answers provided by trainees in University A for the paired answers (for Tiers 1 and 2). An overview shows that half (9) of the items $(2,3,5,7,8,9,11,12,13$, and 15) were assumed to have no chemical bonds. Some of these were dimmers, lattices and even simple diatomic molecules. A critical analysis showed that these species presented diverse bond types, some of which were correctly identified in other species. Upon what bases then were these wrongly assigned ones not to have any chemical bonds? This clearly demonstrated a weakness in trainees' mental structures about chemical bonding with no regular display of a reasoning trend. The items whose bond types were highly identified were oxygen gas, sulphur, carbon dioxide and the ammonia molecule. Nevertheless, some trainees ascribed wrong reasons for the existence of the chemical bonds in them. Ionic bonding appeared to be the highest wrongly assigned chemical bond, as $13(72 \%)$ out of the 18 species were labelled as having ionic bonds, followed by covalent and hydrogen bonds. The double bond in the carbon dioxide molecule was the least identified and explained. It was correctly identified as a covalent bond but not as a double bond (with a sigma and a pi bond), which was also correct. In some cases no attempts were made at choosing chemical bonds displayed as lattices.

The analysed answers for individual items and performance for University B are shown in Table 5.
Table 5. Analysis of items for University B $(\mathrm{N}=39)$

\begin{tabular}{|c|c|c|c|c|}
\hline Item & $\mathbf{C}$ & $\begin{array}{l}\text { Correct } \\
\text { answers }\end{array}$ & $\mathbf{W}$ & $\begin{array}{l}\text { Wrong } \\
\text { answers }\end{array}$ \\
\hline $\begin{array}{l}\text { 1. } \mathrm{NaCl} \\
\text { lattice }\end{array}$ & 29 & Ionic & 10 & $\begin{array}{l}\text { Covalent; } \\
\text { metallic }\end{array}$ \\
\hline $\begin{array}{l}\text { 2.Diamond } \\
\text { lattice }\end{array}$ & 18 & Covalent & 21 & $\begin{array}{l}\text { Network; } \\
\text { dative } \\
\text { covalent }\end{array}$ \\
\hline $\begin{array}{l}\text { 3. } \mathrm{C}_{6} \mathrm{H}_{6} \\
\text { molecule }\end{array}$ & 15 & Covalent & 24 & $\begin{array}{l}\text { Triple } \\
\text { bond; H- } \\
\text { bonding; } \\
\text { carbon } \\
\text { bonding; } \\
\text { no idea }\end{array}$ \\
\hline $\begin{array}{l}\text { 4.Cu (s) } \\
\text { lattice }\end{array}$ & 8 & Metallic & 31 & $\begin{array}{l}\text { Covalent; } \\
\text { ionic; none }\end{array}$ \\
\hline $\begin{array}{l}\text { 5.HF } \\
\text { molecule }\end{array}$ & 11 & $\begin{array}{l}\text { Covalent; } \\
\text { polar }\end{array}$ & 28 & $\begin{array}{l}\text { Ionic; } \\
\text { dipole; H- } \\
\text { bonding }\end{array}$ \\
\hline 6. $\mathrm{H}_{2} \mathrm{O}(\mathrm{l})$ & 26 & $\begin{array}{l}\text { Covalent; } \\
\text { polar; H- } \\
\text { bonding; } \\
\text { VDF; } \\
\text { dipole- } \\
\text { dipole }\end{array}$ & 13 & Ionic \\
\hline $\begin{array}{l}\text { 7. } \mathrm{F}_{2} \\
\text { molecule }\end{array}$ & 25 & Covalent & 14 & $\begin{array}{l}\text { Ionic; } \\
\text { molecular }\end{array}$ \\
\hline $\begin{array}{l}\text { 8. } \mathrm{NaNO}_{3}(\mathrm{a} \\
\text { q) }\end{array}$ & 12 & $\begin{array}{l}\text { Covalent; } \\
\text { induceddi } \\
\text { pole }\end{array}$ & 27 & $\begin{array}{l}\text { Ionic; } \\
\text { metallic; } \\
\text { molecular }\end{array}$ \\
\hline 9. $\mathrm{O}_{2}(\mathrm{~g})$ & 27 & $\begin{array}{l}\text { Covalent; } \\
\text { VDF; } \\
\text { double } \\
\text { bond }\end{array}$ & 12 & $\begin{array}{l}\text { No bond; } \\
\text { intermolec } \\
\text { ular; } \\
\text { dipole- } \\
\text { dipole }\end{array}$ \\
\hline $10 . S_{8}$ & 20 & Covalent & 19 & $\begin{array}{l}\text { Metallic; } \\
\text { hydrogen }\end{array}$ \\
\hline $\begin{array}{l}11 . \mathrm{Na} \\
\text { atom }\end{array}$ & 10 & $\begin{array}{l}\text { Intra- } \\
\text { atomic } \\
\text { forces of } \\
\text { similar } \\
\text { nature }\end{array}$ & 29 & $\begin{array}{l}\text { Ionic; } \\
\text { metallic }\end{array}$ \\
\hline $\begin{array}{l}\text { 12. } \mathrm{AlCl}_{3} \\
\text { dimer }\end{array}$ & 8 & $\begin{array}{l}\text { Polar; } \\
\text { dative } \\
\text { covalent }\end{array}$ & 31 & $\begin{array}{l}\text { Metallic; } \\
\text { ionic; } \\
\text { dipole }\end{array}$ \\
\hline $\begin{array}{l}\text { 13. } \mathrm{CO}_{2} \\
\text { molecule }\end{array}$ & 17 & $\begin{array}{l}\text { Covalent; } \\
\text { polar; } \\
\text { double } \\
\text { (sigma + } \\
\text { pi) }\end{array}$ & 22 & $\begin{array}{l}\text { Intermolec } \\
\text { ular }\end{array}$ \\
\hline $\begin{array}{l}14 . \mathrm{CH}_{3} \mathrm{CO} \\
\mathrm{OH} \text { dimer }\end{array}$ & 3 & $\begin{array}{l}\text { Covalent; } \\
\text { polar; H- } \\
\text { bonding }\end{array}$ & 36 & $\begin{array}{l}\text { In-dipole; } \\
\text { induced } \\
\text { dipole }\end{array}$ \\
\hline 15. $\mathrm{I}_{2}$ Lattice & 11 & $\begin{array}{l}\text { Covalent; } \\
\text { VDF }\end{array}$ & 28 & $\begin{array}{l}\text { Ionic; } \\
\text { metallic; } \\
\text { none; } \\
\text { dipole }\end{array}$ \\
\hline $16 . \mathrm{NH}_{3}$ & 7 & Covalent; & 32 & Dative; \\
\hline
\end{tabular}




\begin{tabular}{|l|l|l|l|l|}
\hline molecule & & polar & & VDF \\
\hline $\begin{array}{l}17 \mathrm{MgO} \\
\text { lattice }\end{array}$ & 28 & Ionic & 11 & $\begin{array}{l}\text { MgO; } \\
\text { polar; } \\
\text { metallic }\end{array}$ \\
\hline $18 . \mathrm{HCl}(\mathrm{l})$ & 18 & $\begin{array}{l}\text { Covalent; } \\
\text { polar; } \\
\text { VDF }\end{array}$ & 21 & $\begin{array}{l}\text { Hydrogen; } \\
\text { intermolec } \\
\text { ular; ionic; }\end{array}$ \\
\hline
\end{tabular}

$\mathrm{VDF}=$ van der Waal's forces; $\mathrm{C}=$ Trainees' correct answers; $\mathrm{W}=$ Trainees' wrong answers

Table 5 shows the answers for each of the paired answers on the diagnostic sheet for University B. Here, nine (9) chemical species, representing 50\%, were wrongly said to possess ionic bonds. Three (4, 9 , and 15) were said to have no chemical bonds. The oxygen molecule and iodine lattice were identified wrongly as not having any chemical bonds, as did trainees in University A. Most of these trainees did not ascribe any reason for these answers. In a focus group interview with University B, it came to light that they were not familiar with the chemical term 'lattice'. They added that copper and iodine exist as monomers. Others said that they existed as dimers instead because of their symbolic representations $(\mathrm{Cu}$ and $\mathrm{I}_{2}$ ), which did not hold for copper. Apart from items numbered $4,5,11,12,14,15$ and 16 which showed many wrong reasons for correctly identified chemical bonds (partial conception), all other items were well answered.

In the focus group interview session diagrams of the diamond lattice, $\mathrm{HF}$ molecule, $\mathrm{NaNO}_{3}(\mathrm{aq})$ and $\mathrm{AlCl}_{3}$ dimer were presented for discussion. Diagrams that showed lattices and dimmers were the least discussed correctly by trainees in both universities. They attested to not being familiar with these descriptions and so could not have imagined the kinds of chemical bonds that would exist between their particles. They supposed that they would be ionic or covalent and so chose any one of them, with certainly wrong interpretations. An overview of scores for the items shows that remediation would be required for all types of chemical bonds in accordance with Hanson and Oppong's [16] reasons for acknowledging the existence of misconceptions.

Some identified implicit misconceptions from the reasoning (second) tier and focus group interview are presented:

1. Sodium atom and sodium chloride lattice have the same kind of chemical bond

2. Sodium chloride contains covalent bonds

3. There is equal sharing of electrons in covalent bonds

4. Ionic bonds occur in majority of compounds

5. Ionic bonding occurs in all compounds

6. Iodine lattice is metallic in nature

7. The iodine lattice has no chemical bonds

8. Bonding in metals is ionic

9. No bonding exists in metals
10. Electron sharing exists in metals

11. A high prevalence of application of the theory of 'full shells' for compound formation

12. The existence/application/ translation of octet rule

13. Non-progressive idea of periodic trends in magnitude on the periodic table

14. Inadequate understanding of the principle of electronegativity and its practical application

15. Oxygen molecule contains hydrogen bonds

16. Covalency exists in all non-crystalline solids

17. Metals contain ionic bonds

18. Wrong interpretation of the metal bonding theory

19. Existence of ionic bonds in crystalline and 'hard' compounds

\section{Discussion}

Analyses of data confirms the assertion that chemical bonding continues to cause difficulties for learners regardless of the fact that it is taught at junior secondary school (age 12-14) and senior secondary school (age $14^{+}$to $17^{+}$). Irrespective of the allowances made for the acceptance of feeble interpretations of the diagrams; more than $10 \%$ of the population in both institutions got less than half the total score. Apart from ionic bonding which was recognised, other bonds such as intermolecular, atomic, van der Waals and metallic bonds were not. If a bond showed significant polarity, the description polar, rather than covalent, was accepted. Thus polar covalent bonding was accepted for items numbered $5,6,8,16$ and 18, which were representations of hydrogen fluoride molecule, water, sodium nitrate solution, ammonia molecule and liquid hydrogen chloride respectively. In the interview session, various unacceptable and conceptually wrong identifications of chemical bonds and reasons came up, especially for the $\mathrm{HF}$ molecule and $\mathrm{NaNO}_{3}$ solution. Some were:

$H F$ is ionic because it has positive and negative ion/charges. Partial charges?... Still charges.

$H F$ is ionic because ' $H$ ' is from the left and ' $F$ ' is from the right of the periodic table.

Aqueous $\mathrm{NaNO}_{3}$ is ionic because all the species there are ions: water and sodium nitrate

Aqueous $\mathrm{NaNO}_{3}$ is ionic because we have sodium and nitrate ions. The water is only a medium.

And for $\mathrm{AlCl}_{3}$ : How can one of them bond with another. They must be single compounds. No, I have never encountered this kind of structure from my teachers.

Diamond will have carbon bonds; network bonds/links. Hydrogen? No.... not like benzene.

Diamond is 'hard' and so it should have had ionic bonds. It also has a regular shape. 
Altogether, analysis of responses showed that trainees had challenges dealing with covalent, metallic, hydrogen and van der Waals forces. They also had challenges understanding the terms 'lattice' and 'dimer'. This may be due to the way that bonding is taught by teachers as if species were discrete units and hardly illustrated dimers and lattices. Ionic lattices are introduced much later in science studies to chemistry major students, well after the concept of discrete chemical bonding is ingrained. The trainees in this study, being representative of those taught in a traditional chemistry curriculum in which bonding concepts are typically taught separately as ionic bonding, covalent bonding and polar covalent bonding, were oblivious of the variations in strength of electronegativities of reacting species in covalent bonds as well as the fact that large differences in electronegativities could result in polarity. The interpretation here is that trainees hold misconceptions about periodic parameters and trends, as well as relationships that can be drawn from these parameters to facilitate their knowledge about chemical bonds. Analyses of trainees' choices show that they were confused about the differences between ionic and covalent bonding. This observation correlates what was made in a study by Taber and Tan [17]. Most Ghanaian chemistry textbooks present the image of matter as if they were discrete entities, which could also be an underlying obstacle to trainees' interpretation of dimers and lattices. This observation about inappropriate presentation of matter in textbooks conforms to what Bergqvist, Dreschsler, De Jong and Rundgren also found in some European chemistry textbooks [12].

Another observation from this current study was that the trainees appeared to assign 'ionic' and 'covalent' bonding to most of the compounds to the neglect of other bond types such as metallic, polar, hydrogen, van der Waals, dipole-dipole, dative and double bonds. The concept of ionic bonding was over-emphasised in their allocation of bond types. Nevertheless, the principles of ionic bonding were not applied. Neither was that of covalency or other bonding principles used to check the veracity of choices. Sodium chloride was easily associated with ionic bonding by trainees as the compound is a common example that Ghanaian teachers use to illustrate the concept of electrostatic or ionic bonding. Trainees in the current study therefore might have imbibed the concept of ionic bonding in $\mathrm{NaCl}$ by rote. Nevertheless, they failed to identify the correct bonds in sodium atom. Hanson [1] made a similar observation in a recent study. A few trainees identified the bonds as 'ionic', 'atomic' and 'metallic', just as they did with sodium chloride. Analyses of their reasons from tier 2and the interview suggest that they face issues of 'familiarity confusion'. As soon as they see 'sodium' or 'sodium chloride', the thoughts of metallic and ionic bonding come to mind without regard for the states in which the species are presented. Interestingly, the probe that was used in this study specifically asked that close attention be paid to the labels under the diagrams as some of them were presented as individual atoms, molecules, lattices and dimers, while others were subsumed in other substances. There was no proper conceptual reasoning pattern as to how their understanding about chemical bonds was applied. What was clear was that if a substance was subsumed in another, only one of the substance's bonding was considered. Trainees showed a confused cognitive understanding of chemical bonds. It was obvious that common sense ideas and pieces of disciplinary knowledge were combined in idiosyncratic ways to make sense of phenomena that were presented to them.

The structural figures or presentations which could have served as clues were not considered. Trainees' prior deficient mental models and cognition were rather applied. Again, the states or forms in which compounds appeared were lost on the trainees. For example, the chemical bonding in aqueous sodium nitrate was wrongly identified by most of the participants as ionic. They only considered the bond type between the sodium cation and the nitrate anion. The presence of water and the fact that the solid or crystal $\mathrm{NaNO}_{3}$ was in solution was disregarded by most of the trainees. The bonding between the sodium nitrate entities and water should have been considered. In one of the institutions, trainees assigned metallic bonding to the aqueous $\mathrm{NaNO}_{3}$ diagram. Metal to non-metal bonding is not a bond type taught at the trainees' level and could not have been assumed. Thus, such an identity was not expected; besides it was wrongly explained. The confusion might have resulted from the presence of ' $\mathrm{Na}$ ' in the compound and trainees' association with metallic bonding in sodium metal. In the $\mathrm{AlCl}_{3}$ dimer they assumed polarity and used the presence of ionic charges as a reason for their choice. From the interview session it was obvious that they did not comprehend nor consider the possibility of a dative covalent bond as existing between the dimer. As explained earlier, the term 'dimer' was clearly not understood by majority of the participants.

Scientific language was identified as yet another challenge for trainees in tier 2. The terms 'lattice', 'dimer', 'liquid' and 'aqueous' were not well differentiated, possibly due to language barriers. In the Ghanaian language there is no distinction between the terms liquid and aqueous. However, these trainees were expected to have risen above this vernacular misconception as the terms are frequently used in senior secondary schools (pre-tertiary) for them to build proper conceptual frameworks about their distinction. Analysis of types of bonds in diagrams that were labelled as 'lattice' and 'dimer' showed that trainees had misconceptions. The chemical bonds were considered as if they were in discrete forms as carbon (diamond), copper and 
iodine atoms. From the interview, the issue of inappropriate instructional strategies, teachers' misconceptions, and text books came up strongly as militating factors to trainees' inabilities to build authentic scientific frameworks. The iodine lattice was explained to possess metallic bonds because it had 'cations dispersed in a sea of electrons'. This misconception could result from teachers who teach students that elements at the bottom of the various groups have properties which suggest metallic character. Iodine is described as a 'solid' but not necessarily 'metallic' in most chemistry text books. A solid species could have covalent, polar covalent, ionic, hydrogen, or van der Waals forces. Yet trainees choose to assign ionic and metallic bonds to solids but not to liquids or gases. Only a handful of trainees assigned covalent bonds to solids and correctly explained their choices. Covalency was attributed to non-solids. This was the reason why diamond was wrongly labelled as ionic and metallic, instead of covalent. Hardness was another reason wrongly associated with ionic and metallic bonding by the trainees in the interview. Interestingly, trainees in this study failed to notice that there was no ionic bond in sodium atom nor any chemical bonding (although intra-atomic forces of similar nature existed). They could not identify that multiple bonds were associated with covalency. Majority of the trainees who identified the double bonds did not intimate that they contained a sigma and a pi bond. The few that identified them was not able to assign reasons for their answers. The word 'covalent' was surprisingly misspelt 'covant' by a couple of trainees.

Analysis of trainees' answers provided in the reasoning part (tier 2) and interview sessions clearly showed that they had difficulties imagining the possible structures of the given species in the probes in real terms. For them, there was no distinction between a copper atom and a copper lattice. It is therefore not surprising that they failed to identify differences between aqueous sodium nitrate and solid sodium nitrate. In order for them to build proper models of the different chemical bonds, remediation involving computer animations or simulations of the various bond types would have to be employed in subsequent teaching and learning processes.

Furthermore, analysis of results in this study showed that though trainees appeared to know about the concept of polarity, they did not associate it at all with electronegativity. They demonstrated very little understanding about how their knowledge about periodic trends could play a useful role in chemical bond formation in the interview. Several trainees appeared to confuse the definition of ionic and covalent bonding. They saw ionic bonding as comprising sharing of electrons. The bonding in metals and ionic compounds appeared a challenge, possibly because of the 'cations in a sea of electrons' concept. They presumed them to be ionic with attractions between the negative and positive ends of an atom. The charged species in metallic lattices are nuclei rather than ions. In this study molecular iodine was assumed to be metallic in nature. In the focus group interview sessions, it came to light that the trainees had weak conceptual structures about the nature of matter. They admitted that periodic parameters were not considered as being contributory factors towards the compounds that they were presented with. They had difficulties in imaging the compounds and so relied on algorithmic procedures. They further attested to having vernacular misconceptions. These findings are in congruence with Taskin and Bernholt's [10]findings about conceptual and cognitive deficiencies about chemical phenomena that are prevalent among university students.

Misconceptions of abstract concepts encountered in the study of chemistry provide opportunity for the development of formal misconceptions. This was identified in trainees' interpretations of scientific terms like 'dimer' and 'lattice'. Although students at each level take several science classes during their schooling in order to learn various science concepts including chemical bonding, the misconceptions identified among trainees in the current study indicates their fragmented understanding of bonding. Students who have strong misconceptions often resist modifying their pre-existing ideas and try to interpret the new acquired knowledge using their preconceptions, even after learning the correct concepts in the classrooms. Thus, new procedures that make students acknowledge the weaknesses in their own knowledge structures have to be adopted. This is important as investigating students' misconceptions reveals insights into their thoughts and enables teachers to see and adopt totally new ways of helping students re-construct their own ideas.

Results of this study provide adequate evidence to support literature $[1,10]$ that students hold misconceptions about chemical bonds. It also identified that trainees' reasoning patterns were erratic, mixed and naïve conceptions which had no scientific grounding. Their explanations did not follow any particular pattern for the identification of chemical bonds but suggested idiosyncrasy in attitude and cognition. These findings could contribute to educators' understanding of some naïve ideas that students have and help them to select appropriate diagnostic and instructional methods. The different types of diagrams used in this study were purposely selected so that trainees would have the chance to interpret diverse representations of chemical species and distinguish among them, as they developed patterns. It served as a simple, lowcost, readily available resource with a powerful inherent diagnostic probe which revealed trainees' misconceptions without support from a facilitator. 
The supposedly simple worksheets were successfully used to unearth trainees' idiosyncratic reasoning patterns and so have a high potential to diagnose other misconceptions in topics for which their use would be applicable. The basis for their use is because worksheets have an inherent ability to engage students in deep thinking, analysis, reflection, interpretation, and collaboration, which are useful learning skills. These learning skills, which are embedded in the second tier (reasoning portion) expose weaknesses in learners' cognitive structures, as was observed in this study.

\section{Conclusion}

From findings made in this study, the tiered diagnostic worksheet provided a quick and easy-toadminister tool that enabled the provision of results in a readily accessible and assessable form. It had the potential to reveal weaknesses in trainees' understanding of chemical bonds better than could have been identified through multiple choice items and non-visual modes. The work sheets also revealed that the trainees had idiosyncratic reasoning patterns about chemical bonds as they had no conceptual reasons for answers to bond types that they worked on. That was an indication of their alternative conceptual frameworks about chemical bonds. In all, 19 unscientific conceptions were identified. Between the two institutions, trainees had a high average of 88.5\% misconceptions about chemical bonding; higher than the level required for remediation.

The tiered worksheets had an inherent characteristic that committed trainees to provide justification for types of chemical bonds that they chose. Thus, they had to reflect, analyse, and make logical deductions for their stands. The second tier of the worksheet was therefore able to initiate higher order learning skills among the trainees as they imagined, analysed, interpreted and reflected on their choices before making conclusions. In this way their original naive deficiencies about chemical bonding were exposed for deconstruction and reconstruction.

\section{Recommendation}

To explore and use research findings to improve chemistry learning, it is important to develop diagnostic instruments that identify misconceptions about chemical phenomena as well as improve curricular resources and teaching approaches. A properly designed tool with concise and clear information could provide enough structure to diagnose students' real problems. Simple and objectively scored diagnostic assessment tests that can be used in the classrooms should be developed by teachers to determine the level of their students' understanding and misconceptions. Again, teachers should be informed about the importance of the determination and alleviation of misconceptions and using appropriate teaching strategies through inservice training courses. Before teaching a concept, such as chemical bonding, teachers should be able to check literature to unearth what is known about misconceptions that students may bring to class and which teaching methods are the best in correcting these misconceptions. This would help them to design better learning environments that help their students to develop concepts authentically, otherwise there would be a gap between research and teaching, and students would pass from grade to grade without fully understanding concepts. Instructional strategies that will expose trainees to systematic visual processes of chemical bond formation are highly recommended.

\subsection{Implication for instruction}

Worksheet activities could be developed at conceptual levels for other chemistry topics for which students' conceptions are found to be faulty. Teachers and curriculum developers could design lessons or worksheet for other topics in chemistry by replicating such tiered activities. The inclusion of variety of teaching methods integrated in classroom lessons would help students to be imaginative, abstract, intuitive and critical thinkers.

\section{References}

[1] R. Hanson, "Assessing the potential of worksheets as a tool for revealing teacher trainees' conceptions about chemical bonds," in CICE-2017 Proceedings, Mississauga, Canada, 2017.

[2] R. K. Coll, N. Taylor, "Alternative conceptions of chemical bonding held by upper secondary and tertiary students," Research in Science \& Technology Education, vol. 19, no. 2, pp. 171-191, 2010.

[3] H. Ozmen, H. Demircioglu and G. Demircioglu, "The effect of conceptual change texts accompanied with animations in overcoming 11th grade students' alternative conceptions of chemical bonding," Computers and Education, vol. 52, no. 3, pp. 681-695, 2009.

[4] R. Hanson, M. Amedeker, E. Oppong and V. Antwi, "Using Microchemistry Activities to Improve Pre-service teachers' Conceptions of Some Inorganic Chemistry Topics," International Journal of Educational Administration, vol. 3, no. 1, pp. 19-40, 2011.

[5] A. K. Griffiths, K. R. Preston, "Grade -12 students' misconceptions relating to fundamental characteristics of atoms and molecules," Journal of Research in Science Teaching, vol. 29, no. 6, pp. 611-628, 1992.

[6] A. G. Harrison, D. F. Treagust, "Secondary students' mental models of atoms and molecules: implications for teaching chemistry," Science Education, vol. 80, no. 5, pp. 509-534, 1996. 
[7] R. F. Peterson, D. F. Treagust and P. Garnett, "Development and application of a diagnostic instrument to evaluate grade- 11 and -12 students' concepts of covalent bonding and structure following a course of instruction," Journal of Research in Science Teaching, vol. 26, pp. 301314, 1989.

[8] K. S. Taber, "Students' understanding of ionic bonding: molecular versus electrostatic framework," School Science Review, vol. 78, pp. 85-95, 1997.

[9] A. Sam, K. Niebert, R. Hanson and C. Aryeetey, "Fusing scientists conceptual correspondences to improve teaching of metal complex isomerism in higher educationAn educational reconstructive process," International Journal of Academic Research and Reflection, vol. 4, no. 1, pp. 54-64, 2016.

[10] V. Taskin, S. Bernholt, "Students' understanding of chemical formulae: A review of empirical research," International Journal of Science Education, vol. 36, no. 1, pp. 157-185, 2014

[11] R. K. Coll, D. F. Treagust, "Exploring tertiary students'understanding of covalent bonding," Research in Science and Technological Education, vol. 20, no. 2, pp. 241-267, 2002.

[12] A. Bergqvist, M. Dreschsler, O. De Jong and S. -N. C. Rundgren, "Representations of chemical bonding models in school textbooks- help or hindrance for understanding?," Chemical Education Research and Practice, vol. 14, pp. 589-606, 2013.

[13] A. H. Akatugba, J. Wallace, "An integrative perspective on students' proportional reasoning in high school physics in a West African context," International Journal of Science Education, vol. 31, no. 11, pp. 14731493, 2009.

[14] K. S. Taber, Chemical misconceptions-Prevention, diagnosis and cure. Volume 1: Theoretical background, London: Royal Society of Chemistry, 2002.

[15] W.-M. Roth, P.-L. Hsu, Analysing communication: Praxis of method, Rotterdam: Sense Publishers, 2010.

[16] R. Hanson, E. K. Oppong, "Ghanaian high school chemistry students' conceptual understanding of stoichiometry and their transalations of problems," Journal of Science Education and Research, vol. 1, no. 1, pp. 1-8, 2015.

[17] K. S. Taber, K. C. Tan, "The insidious nature of 'hard core'alternative conceptions:Implications for the constructivists research programme of patterns in high school students' and pre-service teachers' thinking about ionisation energy," International Journal of Science Education, vol. 33, no. 2, pp. 259-297, 2011.

\section{Appendix A: Focus group interview schedule (One model shown)}

Consider the model below:

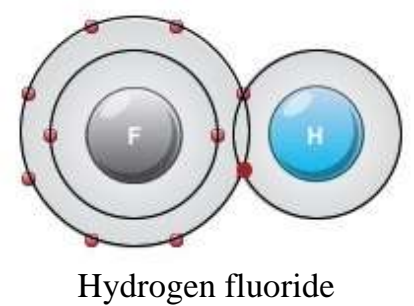

1. What kind of chemical bonds could be found in the hydrogen fluoride molecule?

2. Why do you think so?

3. What are the constituent elements and the oxidation states that they could present?

4. From which groups and periods are the constituent elements coming from?

5. How do periodic parameters differ along the said groups and periods?

6. What bond types are likely to be possible during compound formation of species from the said groups? 